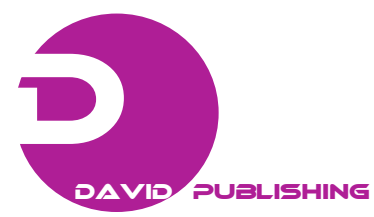

\title{
Efficiency in Boiler Feed Pumps for Industrial Steam Generation
}

\author{
Guilherme Filippo Filho \\ Campus Guaratinguetá, UNESP (Universidade Estadual Paulista), Guaratinguetá, SP 12516-410, Brazil
}

Received: February 14, 2014 / Accepted: March 31, 2014 / Published: June 30, 2014.

\begin{abstract}
This paper presents some opportunities to improve feedwater system efficiency for industrial boilers, usually consisting of multistage centrifugal pumps driven by three-phase induction motors. There is abundant literature on the efficiency in steam boilers. However, few deal exclusively with feedwater systems. The total horsepower in boiler feed pumps and the corresponding energy consumption estimated for Brazilian industries are as follows: $110.5 \mathrm{MW}_{\mathrm{E}}$ of motor driven power and a yearly electricity consumption of $442 \mathrm{GWh}$ for a population of 7,800 steam boilers, approximately. It is estimated that there can be an efficiency improvement in feedwater systems for industrial boilers of $30 \%$ on average. To a large extent, these opportunities reside in older boilers that are very common in the Brazilian industrial sector. The most common causes for the low efficiency of feedwater systems are: the control loop of the feedwater, oversized boilers and excessive operational pressure set. Sometimes, the boiler feedwater system can present more than one problem simultaneously. Any kind of solution involves some form of intervention in boiler feed pumps, such as: impeller trim, speed regulation, new pump and number of pumps. Each problem may have more than one solution. Three distinct industrial steam generation facilities were selected in which common inefficiencies are present. The suggested solutions were analyzed. In these three cases, the improvement in efficiency can get to $37 \%$.
\end{abstract}

Key words: Industrial boiler, boiler feed pump, industrial energy efficiency.

\section{Introduction}

Steam can be used for power generation, process and space heating. Boilers for power plants are very large and their characteristics are very specific. On the other hand, boilers for space heating are usually small and not used in Brazil. Intermediate boilers are predominant in the industrial sector. The steam produced is used for a wide range of heating processes. In large industries, steam can be used for the cogeneration of electricity.

Steam boilers can be classified by their thermal capacity $\left(\mathrm{MW}_{\mathrm{T}}\right)$ or by steam production $(\mathrm{t} / \mathrm{h})$. Fig. 1 illustrates the range of boiler applications [1].

This paper deals exclusively with industrial boilers. In general, the thermal capacity of industrial boilers

Corresponding author: Guilherme Filippo Filho, associate professor, research field: industrial energy efficiency. E-mail: gfilippo@feg.unesp.br. ranges between $3 \mathrm{MW}_{\mathrm{T}}$ and $300 \mathrm{MW}_{\mathrm{T}}$, at some point between $4 \mathrm{t} / \mathrm{h}$ and $400 \mathrm{t} / \mathrm{h}$ of steam output. Usually, boilers with less than $30 \mathrm{t} / \mathrm{h}$ of output are of the firetube type, and while the ones with over $30 \mathrm{t} / \mathrm{h}$ are of the watertube type. Feedwater pumps and draft fans are the main apparatuses driven by electric motors in boilers to generate steam for industrial purposes. Both sets of equipments have numerous opportunities for improvement in their energy performance. However, in industrial facilities, the thermal efficiency of boiler receives greater attention due to fuel consumption. The efficiency of these systems is considered only in large boilers of power plants. This paper is going to present some opportunities to improve the feedwater system efficiency for industrial boilers, usually consisting of multistage centrifugal pumps driven by three-phase induction motors. 


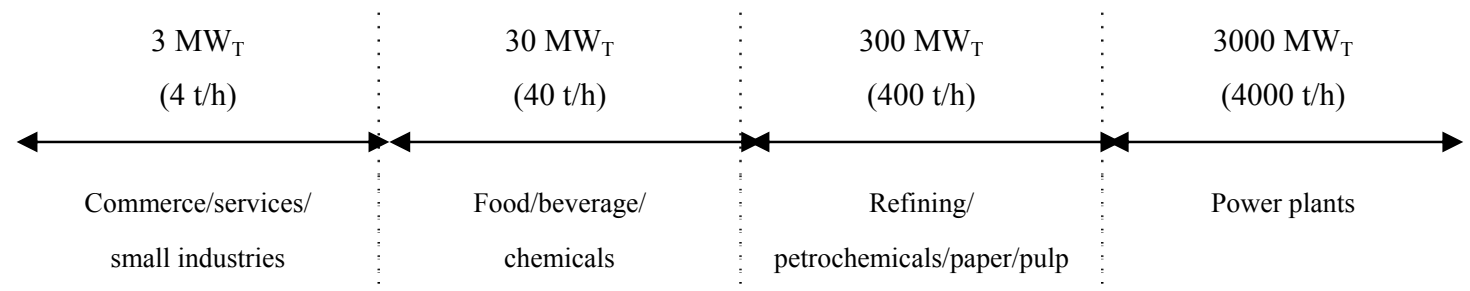

Fig. 1 Range of boiler applications.

The total installed horsepower in boiler feed pumps and the corresponding energy consumption were estimated for Brazilian industries. There is no such data survey in Brazil. This estimate was performed through relations based on available data from the USA. Basic pieces of information were presented to support the energy efficiency assessment of pumps, including flow control systems. The most common causes of inefficiency were identified. The three main reasons were analyzed based on real situations of different industrial plants. It is estimated that the efficiency improvement in feedwater systems for industrial boilers can reach $30 \%$ on average.

\section{Inventory of Industrial Boilers}

An inventory was conducted in the USA. It indicates that there are about 43,000 boilers in the industrial sector with a total capacity of $470 \mathrm{GW}_{\mathrm{T}}$ [1]. The average capacity of boilers is $11 \mathrm{MW}_{\mathrm{T}}$. Their energy consumption is estimated at $6,500 \mathrm{TBtu}\left(154 \times 10^{6}\right.$ toe $\left(\left(^{*}\right)\right.$ toe: tons of oil equivalent $\left.\left.=42.000 \mathrm{MJ}\right)\right)$. This represents between $35 \%$ and $37 \%$ of total fuel consumption in the industrial sector $[1,2]$.

Approximately 21,000 industrial installations have boilers, i.e., $10 \%$ of all installations. About $76 \%$ of boilers are over 30 years old. For large boilers, this percentage decreases to $66 \%$. Only $7 \%$ of the total capacity of boilers is less than 10 years old [1].

The boiler market grows quickly during the industrial development of a country and tends to decline to a stable substitution market after the industrialization process. Their growth in sales is currently concentrated in developing countries, especially China and India [3].

The inventory shows that five industries account for
$71 \%$ of the total population of boilers and $82 \%$ of installed capacity. They are: pulp and paper, chemical, oil refining, food and beverage, and primary metals. Another study [2] reports that only four segments account for $88 \%$ of total fuel consumption for steam generation. They are: (1) pulp and paper; (2) chemical; (3) oil refining; (4) food and beverage. In these industries, the shares of energy with steam generation in relation to the total fuel consumption are $75 \%, 44 \%$, $31 \%$ and $52 \%$, respectively $[2,4]$. The graphs in Fig. 2 show the participation of boilers in each segment with respect to the total population, capacity and consumption of these four industries.

In Brazil, there are no reliable statistic terms on steam generation. A rough estimate could be made by applying the data from the U.S. to the actual Brazilian consumption. Table 1 shows the total fuel consumption of four industries in Brazil [5], and the estimated consumption for steam generation considering the indices of the U.S.

Assuming that these industry segments represent $88 \%$ of the total consumption for steam generation, as it occurs in the U.S., it is concluded that the final consumption is $29.3 \times 10^{6}$ toe, or about $19 \%$ of the U.S. consumption.

Based on American studies [1], with a total capacity of $470 \mathrm{GW}_{\mathrm{T}}$ and an annual consumption of $154 \times 10^{6}$ toe, it follows that the average operational time per year was estimated at 4,000 hours. Likewise, the Brazilian capacity would be $85.5 \mathrm{GW}_{\mathrm{T}}$. The average capacity of industrial boilers in the U.S. is $11 \mathrm{MW}_{\mathrm{T}}$. Considering the same average for Brazil, it is inferred that the population of Brazilian boilers would be on the order of 7,800 units.

A thumb rule widely used in Brazil believes that 1 
Population

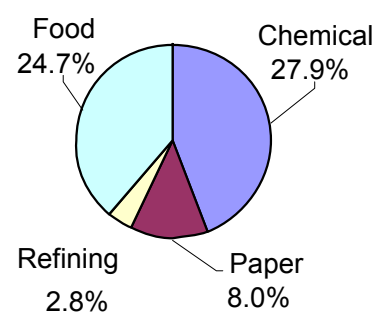

Capacity

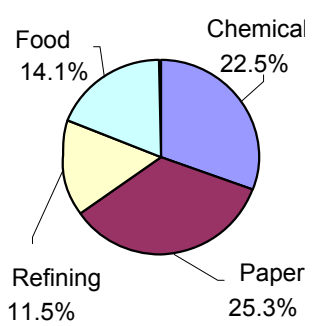

Consumption

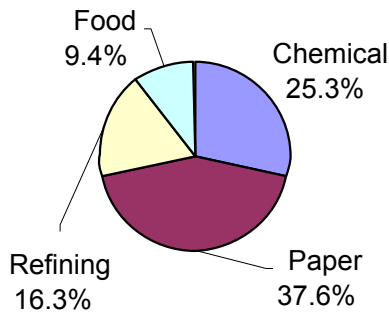

Fig. 2 Participation of boilers in the US industrial sector.

Table 1 Estimation of energy consumption for industrial steam generation in Brazil.

\begin{tabular}{llll}
\hline Industry & $\begin{array}{l}\text { Total consumption } \\
\left(10^{3} \text { toe }\right)\end{array}$ & $\%$ Steam gen & Cons. Steam gen $\left(10^{3}\right.$ toe $)$ \\
\hline Paper and pulp & 8,540 & $75 \%$ & 6,405 \\
Chemical & 5,450 & $44 \%$ & 2,398 \\
Refining $^{\text {a }}$ & 20,376 & $31 \%$ & 6,316 \\
Food and beverage & 20,630 & $52 \%$ & 10,727 \\
Subtotal & 54,996 & & 25,846 \\
\hline
\end{tabular}

\footnotetext{
(a) includes refinery, ethanol plants, natural gas processing, etc. [5].
}

toe generates 15 tons of steam, i.e., the average boilers efficiency is $70 \%$. This represents an average steam production of $110 \times 10^{3} \mathrm{t} / \mathrm{h}\left(29.3 \times 10^{6}\right.$ toe $\times 15$ t/toe $/ 4,000$ h). Assuming, as in the case of the U.S., that the medium pressure of steam produced is $2.2 \mathrm{MPa}(\approx$ 22 bar) and the average efficiency of the motor and pump assembly is $65 \%$, the drive power involved would be of about $110.5 \mathrm{MW}_{\mathrm{E}}$ (Eq. (1)), and an electricity consumption of $442 \mathrm{GWh}$ per year.

\section{Boiler Feed Pump}

The motor power (W) to drive the pump is given by Eq. (1):

$$
P_{\text {ele }}=\frac{\gamma \cdot Q \cdot H_{p}}{\eta_{p} \cdot \eta_{m}}
$$

where, $\gamma$ is the specific weight at feedwater temperature $\left(\mathrm{N} / \mathrm{m}^{3}\right), Q$ is the flow rate $\left(\mathrm{m}^{3} / \mathrm{s}\right), H_{P}$ is the total pump discharge head (m), $\eta_{P}$ is the pump efficiency and $\eta_{m}$ is the motor efficiency.

The total head required is obtained by adding the following parcels: steam pressure in the boiler $(p / \gamma=$ cte), head loss in piping $\left(h_{f} \approx \mathrm{k} \cdot \mathrm{Q}^{2}\right)$, and geometric height difference between the boiler and the deaerator $\left(h_{g}=\right.$ cte). The head loss in piping involves losses in flow control valves, check valves, stop valves, fittings, pipes (including passes for economizers and super heaters, if there is any), and other devices. Typically, the steam pressure accounts for approximately $80 \%$ of the total head at a nominal pump flow rate.

$$
H_{b}=\frac{p_{v a p}}{\gamma}+h_{f}+h_{g}
$$

The centrifugal pump characteristic curve $(H x Q)$ can be approximated, as Eq. (3):

$$
H_{p} \cong H_{0}-a \cdot Q-b \cdot Q^{2}
$$

where, $\mathrm{a}$ and $\mathrm{b}$ are constants for each pump, $H_{0}$ is the shut-off head $(\mathrm{m})$ and $Q$ is the flow rate $\left(\mathrm{m}^{3} / \mathrm{s}\right)$. The system operating point is given by $H_{P}=H_{b}$.

Fig. 3 shows the characteristic curves of the pump $\left(H_{P} x Q\right.$ and $\left.\eta_{P} x Q\right)$, and the feedwater system of an industrial boiler $\left(H_{b} x Q\right)$. The figure on the left shows two distinct points of operation, increasing the valve control opening along the path from 1 to 2 . The figure on the right shows the same change in flow produced by a pump speed increase where the valve opening is kept constant. By applying Eq. (1), it is obvious that the 


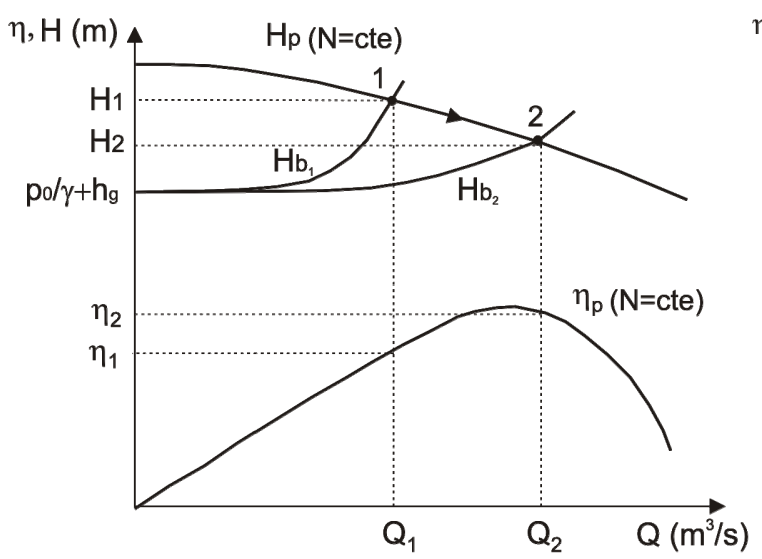

Fig. 3 Flow control by throttling and variable speed.

energy efficiency for the flow variation is greater in the second case.

For pump sizing, seven steps should be considered [6]: number of pumps, feedwater control type, total head of the system $\left(H_{b}\right)$, discharge $(Q)$, NPSH (net positive suction head) required, protection for minimum flow, and the verification of the conditions established by ASME (American Society of Mechanical Engineers).

If the steam plant is "base loaded" with very little load swing, one pump may be used to serve multiple boilers. Otherwise, there must be at least one pump for each boiler. The modulating feedwater control should be used. The calculation of $H_{b}$ has already been explained above. Special attention must be given to the NPSH, since the feedwater is generally at an elevated temperature. A "gap" between the available NPSH and the one required by the pump must be sufficient to avoid cavitation problems. If it is necessary to protect the pump for a minimum flow by recirculation, it should be $20 \%$ of the flow at the best efficiency point of the pump $\left(Q_{B E P}\right)$, or what is stated by the manufacturer.

The calculation of the net pump flow rate $\left(Q_{n o m}\right)$ must take into account the boiler evaporation rate $\left(Q_{E V}\right)$ and its catch-up capacity $\left(Q_{C T}\right)$. The evaporation rate includes the steam flow to the system, purge, and possible diversion to deaerator. The catch-up capacity should be $25 \%$ of $Q_{E V}$ for modulating control and $100 \%$ of $Q_{E V}$ for on/off control. The ASME Code requires that the pump is able to maintain a flow rate

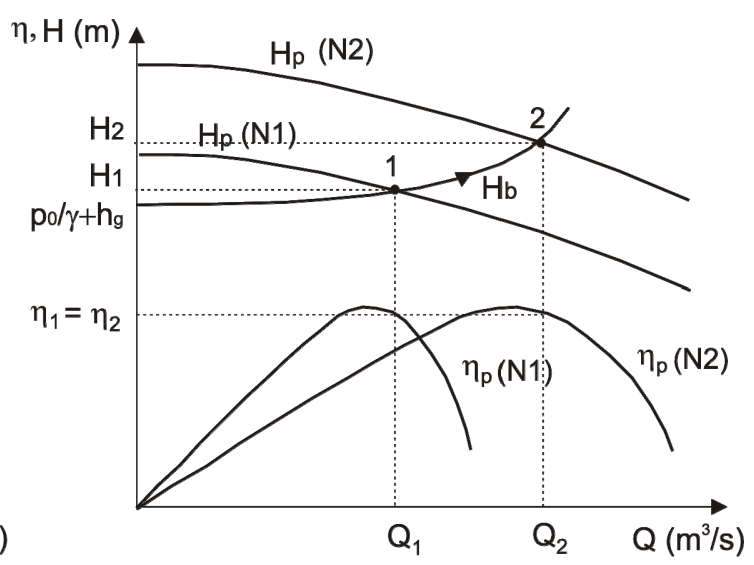

that is equal to evaporation rate at pressure 3\% greater than set pressure to the safety valves of the boiler.

\section{Feed Water Control}

Steam load in industrial facilities is not constant. It varies throughout the day (time variation) and along the year (seasonal variation). So, feedwater flow should also vary. This variation is obtained by throttling the flow control valve or the variable speed pump, as illustrated in Fig. 3. The control system of the boiler controls these devices. Signals obtained by level sensors are processed by means of an inverse relation, that is, the higher the water level in the boiler is, the lower the flow rate gets, and vice versa. Differential pressure signals may also be used. The water level in the boiler must remain within maximum and minimum limits. Excess water causes flooding of separation moisture devices, causing drag of the liquid phase along with steam into the system. Lack of water can cause overheating of the heat exchange surfaces.

When the steam demand increases, the formation of bubbles in water increases, the average density of the mixture reduces, and it increases the water level in the boiler, even in absence of water intake. This phenomenon is known as "swell". In contrast, if the steam demand decreases, the average density of the mixture increases and lowers the water level in the boiler, which is a phenomenon called as "shrink". These phenomena cause unwanted fluctuations in the boilers feedwater. 


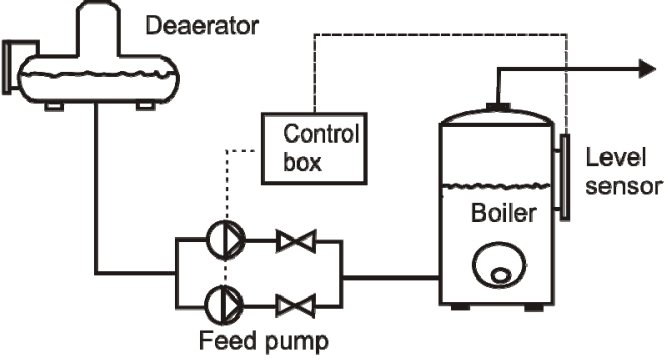

(a)

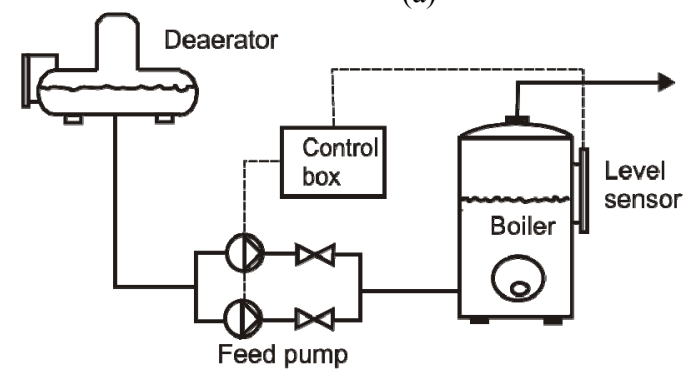

(c)

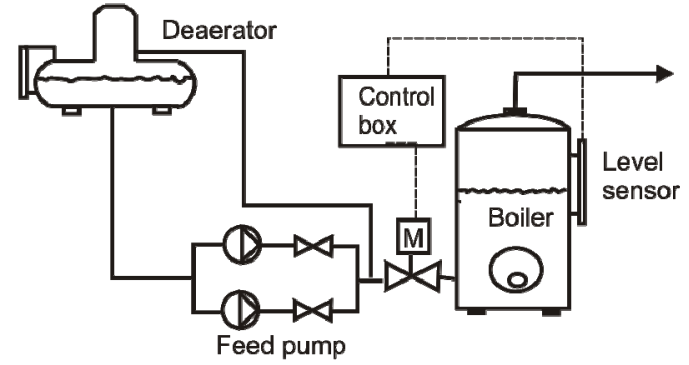

(b)

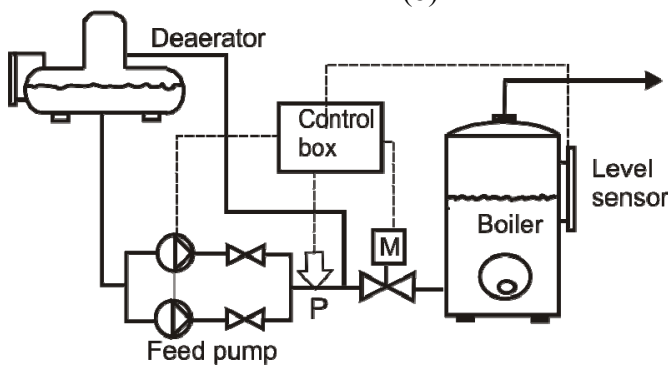

(d)

Fig. 4 Modes of boiler level control.

There are four modes for boiler level control: (a) turning the pump on/off; (b) through feed control; (c) variable speed pumps; (d) the combination of the last two, as Fig. 4 shows a schematic of these modes [7].

For the aforementioned reasons, the on/off control is applied only for small boilers. When the water level falls, the pump starts pumping a large quantity of relatively cold water into the boiler. This will reduce the quantity of steam in the boiler and result in a pressure drop. Water may possibly be dragged along with the steam into the system. The other modes are applied in larger boilers, known as modulating controls. The control loop can have one (level), two (level and steam flow rate), or three elements (level, steam and water flow) $[8,9]$. The signal processing of steam and water flow elements allows a smooth oscillation of the boiler feed. In the case of control by means of throttling valves, whether being with or without variable speed pump, the existence of recirculation systems is strongly recommended, i.e., a link between the pump discharge and the deaerator. This ensures a minimum pump flow in order to prevent damage by overheating and other detrimental effects of reduced flow in pumps.

\section{Opportunities for Efficiency Improvement}

There is abundant literature on the efficiency in steam boilers [10-12]. However, few deal exclusively with feedwater system. As it can be seen from Eq. (1), the input power of the pumps depends on pressure (discharge head), flow rate, and pump efficiency. All these variables are linked to characterize the performance of the pump. Based on studies of various steam generation plants for industrial purposes, it was observed that some inadequacies are present routinely. Usually, there is more than one mismatch in the same plant. A significant part of this situation is due to the age of the facilities with their old projects and equipment. Highlighted, are three very common situations:

- Control loop of the feedwater system. Typically, there are boilers with a modulating control of a single element, namely the control of the throttling valve is done solely with the water level signal of the boiler. The pump flow becomes very swinging, i.e., it fluctuates from very low flows to one beyond the rated condition. Sometimes, the pump reaches a shut-off state briefly. This causes severe vibration due to hydraulic imbalance and a severe degradation of 
mechanical conditions, especially the sealing system. Efficiency is greatly reduced by low flow.

- Oversized boiler. Sometimes the boiler is selected for attending a particular load which was not observed. There are several reasons for this fact. In this case, the pump operates at a very low flow which is far from its BEP (best efficiency point). Thus, the pump efficiency can be dramatically reduced. It is well known that pumps continuously operating with very low flows are subject to a higher failure rate.

- Steam pressure reduction. It is not uncommon to find facilities in which the set pressure of the boiler is higher than the processes needs. As an example, a certain industrial plant had a small boiler $(5 \mathrm{t} / \mathrm{h})$ with pressure set to $10 \mathrm{bar}_{\mathrm{g}}$. The saturated steam in this condition has a temperature of $183{ }^{\circ} \mathrm{C}$. None of the heating processes required temperature that is higher than $164{ }^{\circ} \mathrm{C}$, or pressure of 6 bar $_{\mathrm{g}}$. Without any major difficulties [12], the boiler could be set to produce saturated steam at $7 \mathrm{bar}_{\mathrm{g}}$, which is sufficient to increase the feedwater system efficiency in 30\%. Another situation found routinely is the steam consumption in two levels of pressure. Parts of the processes demand 6 barg $_{\mathrm{g}}$ and others 18 bar $_{\mathrm{g}}$, for instance. In this case, the boiler generates steam in $18 \mathrm{bar}_{\mathrm{g}}$ and the level of $6 \mathrm{bar}_{\mathrm{g}}$ is obtained by pressure reducing valve. Therefore, the energy dissipated in the valve is supplied by the pump.

Three cases of each of the aforementioned situations are presented below.

\section{Cases}

\subsection{Case 1: Inadequate Control Loop}

Watertube boiler, natural gas, $30 \mathrm{t} / \mathrm{h}, 2$ feedwater pumps (1 stand-by), LIC (loop control with 1 element), 25 years, feedwater at $60^{\circ} \mathrm{C}$.

Note: draft fan motor, $100 \mathrm{cv}$.

Centrifugal pump, barrel type, 7 stages, gland packing, 3,500 rpm, $60 \mathrm{cv}$.

Design: $Q_{p r o j}=39 \mathrm{~m}^{3} / \mathrm{h}, H_{p r o j}=268 \mathrm{~m}, \eta_{p r o j}=66 \%$.

Nominal: $Q_{\text {nom }}=30 \mathrm{~m}^{3} / \mathrm{h}, H_{\text {nom }}=341 \mathrm{~m} ; \eta_{\text {nom }}=64 \%$.

Characteristic curves (adjusted):

$$
\begin{gathered}
H_{P}=329.5+1.005 Q-0.0725 Q^{2} \\
\eta_{P}=0.0002 Q^{3}-0.0658 Q^{2}+3.9026 Q-0.1548
\end{gathered}
$$

Operating time: 24 hour/day.

Monthly steam production (t): see Fig. 5 .

Load of a typical day: see Fig. 6 and Table 2.

The considered average production of steam during the day was $20.6 \mathrm{t} / \mathrm{h}$. The total energy consumption was $798 \mathrm{kWh}$. If a control system with 3 elements could ensure a uniform discharge of $20.6 \mathrm{t} / \mathrm{h}$, the total head of the pump would be $319.4 \mathrm{~m}$ and its efficiency of $54 \%$. With this, the consumption in over 24 hours would be of $796 \mathrm{kWh}$. Therefore, there is no energy efficiency improvement to be taken into account.

Fig. 7 shows the feedwater flow during 1 hour of a typical day (measurements every 2 seconds).

The swing of the discharge causes loud noise and vibration in the pump. The gland packing failure rate is quite high. If the production were uniform, the problem of damage to the gland packing would be greatly improved.

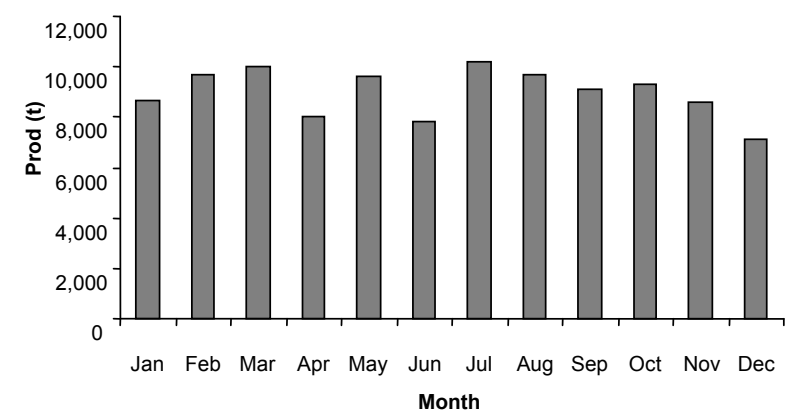

Fig. 5 Monthly production (t).

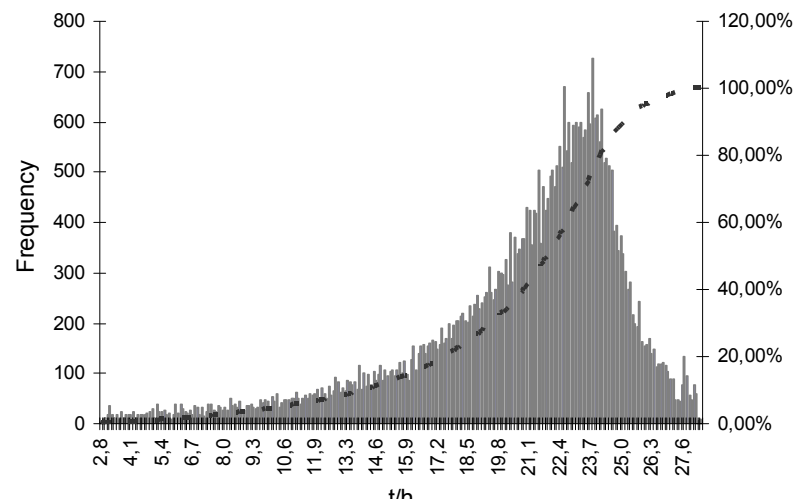

Fig. 6 Histogram and cumulative output percentage on a typical day (24 hours). 
Table 2 Steam production characteristics on a typical day-Average production for bands.

\begin{tabular}{lllll}
\hline Bands $(\mathrm{t} / \mathrm{h})$ & $<15 \mathrm{t} / \mathrm{h}$ & $15-20 \mathrm{t} / \mathrm{h}$ & $20-25 \mathrm{t} / \mathrm{h}$ & $>25 \mathrm{t} / \mathrm{h}$ \\
\hline$\%$ time & 12.2 & 21.3 & 55.2 & 11.3 \\
Avg. Output $(\mathrm{t} / \mathrm{h})$ & 10.76 & 18.00 & 22.73 & 26.17 \\
$H_{P}(\mathrm{~m})$ & 331.9 & 324.1 & 314.9 & 306.2 \\
$\eta_{P}(\%)$ & 34.4 & 49.9 & 56.9 & 60.5 \\
$P_{P}(\mathrm{~kW})$ & 28.3 & 31.8 & 34.3 & 36.1 \\
$E E(\mathrm{kWh} /$ day $)$ & 82.86 & 162.56 & 454.4 & 97.9 \\
\hline
\end{tabular}

$P_{P}$ : pump input power, $E E$ : input energy.

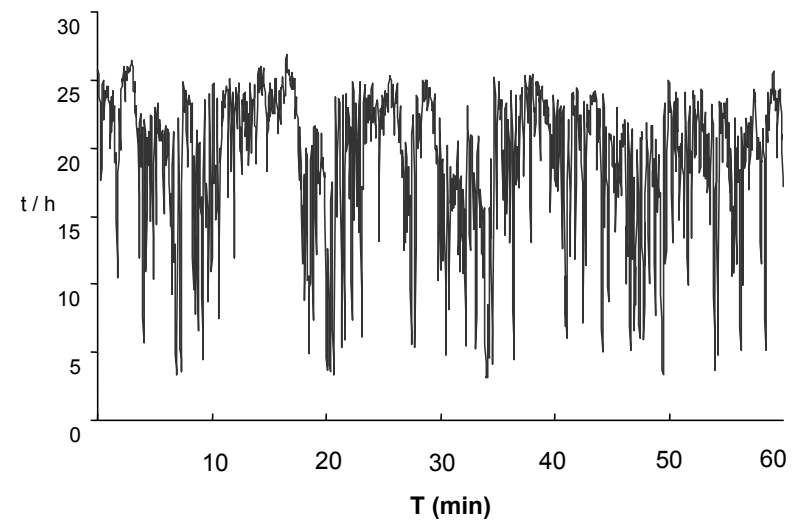

Fig. 7 Boiler feedwater flow rate for 1 hour.

It is possible to introduce a frequency inverter under the control loop of 3 elements. In this case, the flow control valve would be kept fully open for operating the pump at design conditions, i.e., $Q=39 \mathrm{~m}^{3} / \mathrm{h}, H_{P}=$ $268 \mathrm{~m}$, and $\eta_{P}=66 \%$. The static head of the system is $197 \mathrm{~m}$. The adjusted curve is given by Eq. (6):

$$
H_{b} \approx 197+0.0467 Q^{2}
$$

With the valve open, head $H_{b}$ is equal to $217 \mathrm{~m}$. Applying $Q=20.6 \mathrm{~m}^{3} / \mathrm{h}$ and $H=217 \mathrm{~m}$, the pump shut-off head equals $H_{0}=227 \mathrm{~m}$ (Eq. (4)). Through similarity ratio (Eq. (7)), one obtains a rotation of 2,900 rpm.

$$
\frac{H_{01}}{H_{02}}=\left(\frac{N_{1}}{N_{2}}\right)^{2}
$$

To determine the input power in this case, it is necessary to estimate the efficiency of the pump. For this, the flow of $20.6 \mathrm{~m}^{3} / \mathrm{h}$ at $2,900 \mathrm{rpm}$ needs to be reflected in the $3,500 \mathrm{rpm}$ curve, applying the similarity relations of Eq. (8).

$$
\frac{Q_{1^{\prime}}}{Q_{2}}=\frac{N_{1}}{N_{2}}
$$

This results in a reflected flow of $24.8 \mathrm{~m}^{3} / \mathrm{h}$. With the application of the efficiency equation, its estimated value is $59.2 \%$ (Eq. (5)). In this new condition, the input power is $20.6 \mathrm{~kW}$. Thus, the daily energy consumption would be of $495 \mathrm{kWh} /$ day for a uniform steam production. The gain is $38 \%$ compared to the previous situation of $798 \mathrm{kWh} /$ day. Fig. 8 illustrates this new condition.

\subsection{Case 2: Oversized Boiler}

Two watertube boilers, sugar cane bagasse, $150 \mathrm{t} / \mathrm{h}$ each, 43 bar $_{\mathrm{g}}, 410{ }^{\circ} \mathrm{C}$, loop control with 3 elements $\left(L I C, F I C_{\text {water }}, F I C_{\text {steam }}\right)$, feedwater at $110^{\circ} \mathrm{C}$.

Note: the power of the primary and secondary fans sum is by $450 \mathrm{cv}$ per boiler.

Two centrifugal pumps, 8 stages, $350 \mathrm{cv}$ each, 3,500 rpm, parallel operation.

Design: $Q_{\text {proj }}=98 \mathrm{~m}^{3} / \mathrm{h}, H_{p r o j}=608 \mathrm{~m}, \eta_{p r o j}=72 \%$.

Nominal: $Q_{n o m}=79 \mathrm{~m}^{3} / \mathrm{h}, H_{\text {nom }}=656 \mathrm{~m}, \eta_{\text {nom }}=68 \%$.

There is a further pump driven by the steam turbine in parallel with the electrical assembly, input power $700 \mathrm{cv}, Q_{p r o j}=196 \mathrm{~m}^{3} / \mathrm{h}, H_{p r o j}=608 \mathrm{~m}$.

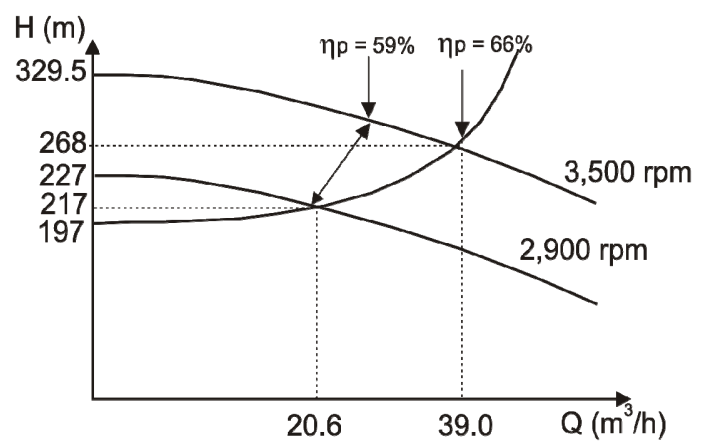

Fig. 8 Pump operating conditions for a steam output of $20.6 \mathrm{t} / \mathrm{h}$. 
Operating time: 220 days/year, 24 hours/day.

The average output and the included blowdown: see Table 3.

The two boilers operate simultaneously. For the average feeding of $118 \mathrm{~m}^{3} / \mathrm{h}$ of the assembly, each pump has a discharge medium under the following conditions:

$$
Q_{o p}=29.5 \mathrm{~m}^{3} / \mathrm{h}, H_{o p}=720 \mathrm{~m}, \eta_{o p}=40 \%
$$

The input power to drive each pump will be $P_{o p}=$ $137.6 \mathrm{~kW}$. In this case, there are four pumps operating simultaneously. The oversizing is evident. It only takes one boiler to meet the demand.

When shutting down one boiler, the operating condition of each pump becomes:

$$
Q_{o p}=59 \mathrm{~m}^{3} / \mathrm{h}, H_{o p}=680 \mathrm{~m}, \eta_{o p}=60 \%
$$

The input power for each pump will be $P_{o p}=173.3$ $\mathrm{kW}$.

The input power in the former situation is $550 \mathrm{~kW} \mathrm{(4}$ $\times 137.6 \mathrm{~kW})$ and in the proposed situation is $347 \mathrm{~kW}(2$ $\times 173.3 \mathrm{~kW})$. An improved efficiency of $37 \%$ is obtained.

\subsection{Case 3: High Pressure (Old Installations)}

Firetube boiler, natural gas, $20 \mathrm{t} / \mathrm{h}, 18$ bar $_{\mathrm{g}}$, feedwater temperature $50{ }^{\circ} \mathrm{C}$, loop control (LIC, $F I C_{\text {steam }}$ ), two feed pumps (1 stand-by).

Centrifugal pump, barrel type, five stages, mechanical seals, $3500 \mathrm{rpm}, 50 \mathrm{cv}$.

Design: $Q_{p r o j}=24 \mathrm{~m}^{3} / \mathrm{h}, H_{p r o j}=235 \mathrm{~m}, \eta_{p r o j}=58 \%$.

Nominal: $Q_{\text {nom }}=20 \mathrm{~m}^{3} / \mathrm{h}, H_{\text {nom }}=240 \mathrm{~m}, \eta_{\text {nom }}=53 \%$.

Operating time: 16 hours/day, 6 days/week.

Average output: $16 \mathrm{t} / \mathrm{h}$.

$Q_{o p}=16 \mathrm{~m}^{3} / \mathrm{h}, H_{o p}=243 \mathrm{~m}, \eta_{o p}=46 \%, P_{o p}=23 \mathrm{~kW}$.

The plant consumes $90 \%$ of the steam at a pressure of $10 \mathrm{bar}_{\mathrm{g}} / 183{ }^{\circ} \mathrm{C}$ and only $10 \%$ at a pressure of 18 $\mathrm{bar}_{\mathrm{g}} / 208{ }^{\circ} \mathrm{C}$. All the steam is generated at $18 \mathrm{bar}_{\mathrm{g}}$, and then reduced to $10 \mathrm{bar}_{\mathrm{g}}$ through pressure reducing valve, as illustrated in Fig. 9. Only one point of the plant consumes steam at 18 bar $_{\mathrm{g}}$. Strictly speaking, this point should have its own heating system, or else the process should be investigated for the possibility of
Table 3 Average output of each boiler (B1 and B2) and the set*.

\begin{tabular}{lllll}
\hline Boiler & B1 $(\mathrm{t} / \mathrm{h})$ & B2 $(\mathrm{t} / \mathrm{h})$ & $\mathrm{B} 1+\mathrm{B} 2(\mathrm{t} / \mathrm{h})$ & $\mathrm{B} 1+\mathrm{B} 2\left(\mathrm{~m}^{3} / \mathrm{h}\right)$ \\
\hline Average & 60.6 & 53.4 & 112.1 & 118 \\
Max & 71.3 & 71.3 & 129.2 & 136 \\
Min & 49.9 & 41.3 & 98.8 & 104 \\
\hline
\end{tabular}

* average, maximum and minimum values for each boiler are not concurrent.

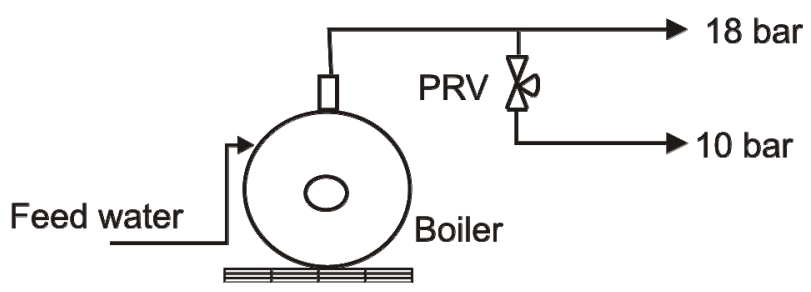

Fig. 9 Plant layout.

reducing its temperature from $200{ }^{\circ} \mathrm{C}$ down to $180{ }^{\circ} \mathrm{C}$. The elimination of this point, by means of another form of heating, could result in reduced operating pressure of the boiler, and thus increasing the efficiency of feedwater. This new situation can be obtained by installing a new pump assembly or by reducing pump speed, similar to that described in Case 1. In the case of a new pump, it has:

Design: $Q_{p r o j}=1.2 \times 20=24 \mathrm{~m}^{3} / \mathrm{h}, H_{p r o j}=130 \mathrm{~m}$, $\eta_{\text {proj }}=52 \%$, pump KSB WL 40/5 stages, 3,500 rpm, $P_{\text {motor }}=30 \mathrm{cv}$.

Nominal: $Q_{o p}=0.9 \times 16=14.4 \mathrm{~m}^{3} / \mathrm{h}, H_{o p}=170 \mathrm{~m}$, $\eta_{o p}=46 \% \geqslant P_{o p}=14.5 \mathrm{~kW}$.

Increased efficiency is $37 \%$.

\section{Conclusions}

Feedwater systems for industrial boilers in Brazil have an estimated installed power of $110 \mathrm{MW}_{\mathrm{E}}$ and an energy consumption of $442 \mathrm{GWh}$ per year. There are opportunities to improve the performance of these systems. Three analyzed cases showed a potential efficiency improvement of $37 \%$. To a large extent, these opportunities reside in older boilers which are very commonly found in Brazilian industries. There is no single solution for all cases. Predominant problems focus on control systems level, in oversizing, and excessive pressure. It is not unusual for a boiler to present more than one problem simultaneously. 
The efficiency of the boiler feedwater in power plants is widely studied. The same does not occur with the intermediate size boilers to generate steam for industrial purposes. The present Article has not presented any technological innovation. It only sought to demonstrate that there is a significant potential for improving energy efficiency in an application where this issue is commonly ignored. It is expected that it will be able to raise awareness among energy managers of industries with high steam consumption, such as the chemical sector, food and beverage, pulp and paper, sugar and ethanol, in addition of refineries and petrochemical plants. The results obtained in the three cases evaluated are above expectations outlined in international literature. In part, this is due to inattention to the problem.

\section{References}

[1] Energy and Environmental Analysis, Inc., Characterization of the US industrial commercial boiler population, Oak Ridge National Laboratory web site May 2005, http://www.eere.energy.gov/manufacturing/.

[2] Energetics, Inc. \& E3M, Inc., Energy use, loss and opportunities analysis: US manufacturing and mines, DOE/EERE web site dec. 2004, http://www.eere.energy.gov/industry (accessed Oct 12,
2012)

[3] Industrial Combustion Boilers, ETSAP (Energy Technology Systems Analysis Programme) [Online], May 2010, Technology Brief I01, www.iea-etsap.org.

[4] Steam System Opportunity Assessment for the Pulp and Paper, Chemical Manufacturing and Petroleum Refining Industries, Main Report [Online], Oct. 2002, DOE/EERE, http://www.oit.doe.gov.

[5] Brazilian Energy Balance 2012, MME/EPE Web site, http://www.epe.gov.br.

[6] Pumps selection and sizing, Application Guidelines, Section 7, Pumps AG 7.1 [Online], Industrial Steam Web site, Jan. 2003, http://www.industrialsteam.com.

[7] Engineering manual-industrial boilers, Grundfos Industry Web site, 2009, http://www.grundfos.com.

[8] E.A. Bega, Instrumentação aplicada ao controle de caldeiras, 3rd ed., Interciência, Rio de Janeiro, 2003.

[9] M.C. Campos, H. Teixeira, Controles típicos de equipamentos e processos industriais, 1st ed., in: E. Blücher (Ed.), São Paulo, 2006.

[10] R. Zeitz, Energy Efficiency Handbook, CIBO-Council of Industrial Boiler Owners [Online], 1997, www.eere.energy.gov/manufacturing/ (accessed Oct 15, 2012).

[11] Improving steam system performance-A sourcebook for industry, DOE/EERE Web site, Oct. 2004, www.eere.energy.gov.

[12] Steam pressure reduction: opportunities and issues, DOE/EERE Web site, Nov. 2005, www.eere.energy.gov. 